\title{
Reflexives and Reciprocal relations in Ga
}

\author{
Ruby Otoo \\ University of Education, Winneba
}

\begin{abstract}
In this paper, we examine the devices that the Ga language uses to express anaphoric relations, especially, such notions as one act on one self (reflexive). 'A acts on $B$ ' and ' $B$ acts on $A^{\prime}$ (reciprocal) and other relationships involving nominal in a particular local domain that results in construing them as having the same referent. This paper, which draws heavily on Carnie (2013, 2002) Haegeman (2006), and Reuland (2001) show that (i) pronouns may function as anaphoric elements in certain syntactic contexts. (ii) reciprocal relations are expressed with verbs and he 'self/body' constructions which serve as the reciprocal marker and (iii) reflexives are marked with the use of verbs which indicate that action is being performed on the subject itself or a possessive pronoun plus he (self) construction.
\end{abstract}

KEY WORDS: Anaphora, Antecedent, Co-reference, Reciprocal, Reflexive

\section{INTRODUCTION}

In generative grammar, Chomsky (1995), Hageman (1991, 2006), and Carnie $(2002,2013)$ identify three types of noun phrases (NPs). Carnie (2013: 147-149) and (Carnie 2002:89-98) explained these NPs as (i) A referring expression which is "an NP that gets its meaning by referring to an entity in the world. (ii) anaphor, which is "an NP that obligatorily gets its meaning from another NP in the sentence," and (iii) a pronoun which is "an NP that may (but need not) get its meaning from another NP in the sentence". The paper focuses on anaphors and how they are realized in Ga. Anaphors are normally divided into two types: reflexives, which are expressed in English with reflexive pronouns such as herself, himself, etc. and reciprocals, which include expressions like each other and one another. Plain pronouns may also function as anaphoric elements in certain discourse contexts; therefore, they will be included in this study of anaphora.

The term "anaphora" is used to refer to the phenomenon in human languages whereby an NP gets its interpretation from another NP within a particular syntactic domain or the context. Anaphoric relation is generally used to refer to the relationship between nominal such that they are construed to be co-referential. The term "anaphor" is used to refer to any form that depends on a syntactic antecedent or some discourse relation for its reference. Carnie (2002:98, 2013:147-149) explains anaphor as "an NP that obligatorily gets its meaning from another NP in the sentence. Haegeman (2006:74) also defines anaphoric elements as "elements that can be used to replace strings of words. Reuland (2001:276) also asserts anaphor as co-argument that must be co-indexed, if there is one. From the definitions given, "while Carnie and Reuland restrict the application of anaphors and anaphoric relations to NPs, Haegeman allows for the application of the terms to other sentence elements such as verb phrase (VPs). This paper will focus mainly on reflexive and reciprocal relations on noun phrases (NPs) in Ga and the devices used to articulate these relations. 
There have been few studies on reflexives and the process of reflexivization in the Akan language. Osam(2002:142; 2008) did a study on reflexives. He opines that "body care actions" are used for reflexives and that whenever there is a competition between the two within the same sentence, it is the locality condition on anaphor interpretation that helps to distinguish a reflexive reading from one that is not a reflexive reading. Other studies on the subject includes Saah(2003, 2007); Haegeman (2006); Reuland (2001); Agbedor(2014) and Mazengia (2014) just to mention a few. My aim in this study is to examine the linguistics devices that the Ga language employs to express (i) how pronouns may function as anaphoric elements in certain syntactic contexts. (ii) reciprocal relations are expressed with verbs and he 'self/body' constructions which serve as the reciprocal marker and (iii) reflexives are marked with the use of verbs which indicate that action is being performed on the subject itself or a possessive pronoun plus he (self) construction. The work is structured as follows: Section 1 presents the introduction, background information about the language in focus, it provides a note on the data and methodology of the study and the pronominal system of Ga. Section 2 discusses ordinary pronouns used as anaphors in Ga. In Section 3, we examine the issues involved in the interpretation of Reciprocal Co-reference. Section 4, we examine the strategies used for reflexive co-reference. The last section, section 5 looks into issues connected with the interpretation of anaphors

\section{Language Information}

Ga is a Kwa language belonging to the Niger- Congo family. Williamson (1989) classifies it as belonging to the Nyo sub-group. It is the indigenous language of the capital of Ghana, Accra. It is spoken in the coastal towns of Osu, La, Teshie, Nungua, Tema, Kpone, as well as in a number of 'smalll towns and villages as far as the borders of the Akyem and Akwapim regions. Ga has two contrastive tones: high and low. Conventionally, tones are hardly marked in the respective orthographies, a practice which is maintained in this study. With regard to the word order, it is no different from its other Kwa neighbors in being SVO.

The data for this paper is drawn from the Ga Methodist hymn book, Ga Bible, recorded utterances heard from the media and excepts from conversations. The recorded conversation is interactive in nature, but not based on a particular topic or subject. The recordings are focused on these places: University of Education, Winneba students and programmes on Obonu FM. I chose this media because a lot of social and political discussions are aired on the radio and the issues discussed will compliment the data for the study. During the analysis, the recordings and the excepts are transcribed orthographically. After that the utterances which involves the anaphor is selected. With the Bible and the hymns, the chapter and the verses containing anaphors will be used for the analysis. The source of the data is coded alongside with the expressions used. The binding theory principles of Haegmann (2006) and Carnie (2013) is adopted for the work.

\section{The Pronominal System of Ga}

All the various ways used to express anaphoric relations in Ga involve the use of personal pronouns. As a result, it is of much important to take a look at the pronouns in the Ga language before we look at the study. The table below shows the pronominal system in Ga. 
Table 1: The Pronouns in Ga
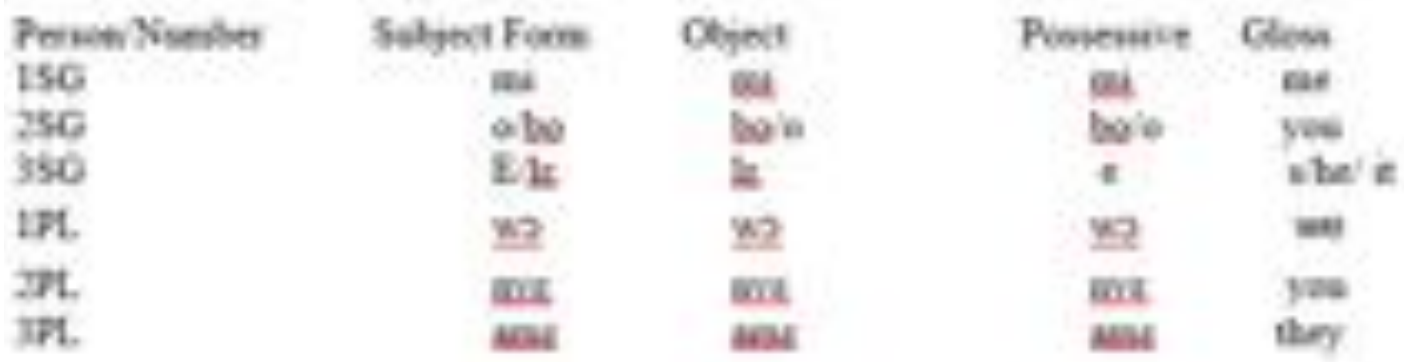

From the above data, all pronouns in Ga have the same form from the subject, object and possessive cases. The possessive pronouns are the same as the accusative forms for all persons except the 3rd person singular / e /. "his /her/its. The subject form of the 2SG / bo / and 3SG $/ \mathrm{l} \varepsilon /$ pronouns is used in emphatic utterances. For example :

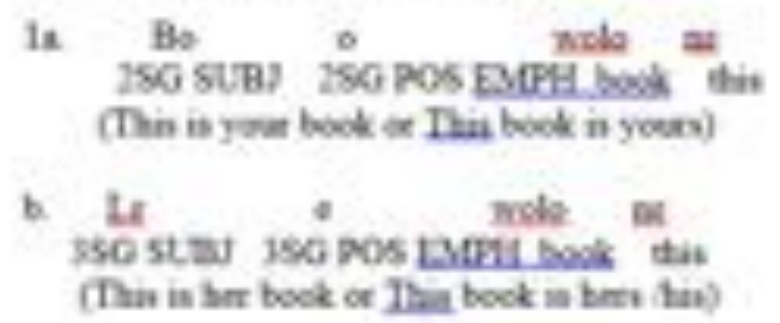

\section{Pronouns Used as Anaphors}

Any pronoun may be anaphoric in the sense that it may refer to an entity already introduced in a context (1a) or in the same sentence (1b). Unlike the case of reciprocals or reflexives where the antecedent and the anaphor (ie reciprocal or reflexive) must occur in the same local domain (ie, the clause containing the anaphor and its antecedent) a pronoun and its antecedent need not be found in the same locality.

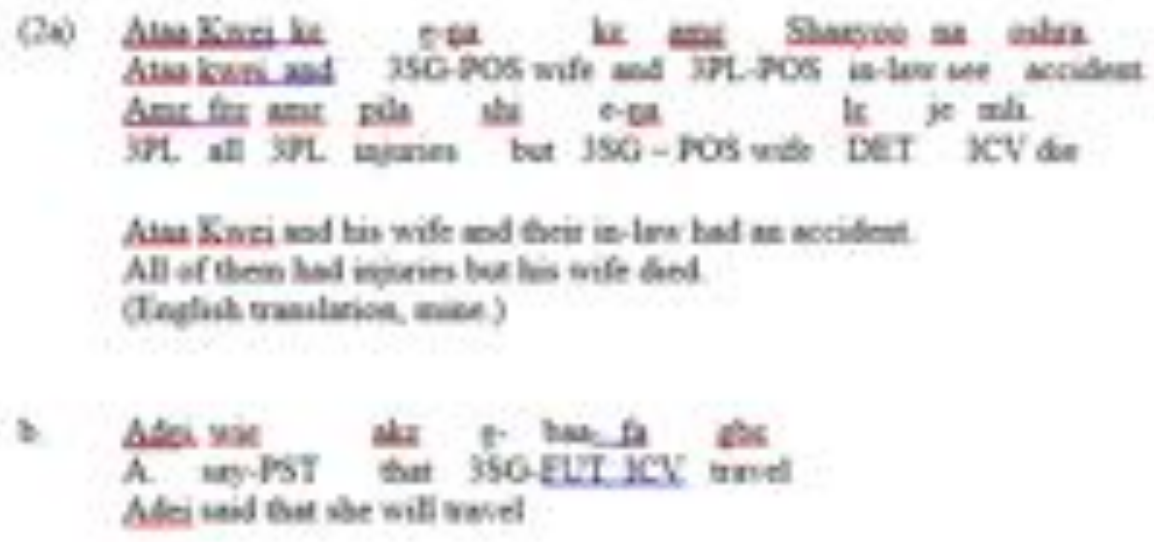

In these examples, the underlined and co-indexed elements are co-referential. In other words, the pronouns e 'his' (la) and e 'her' in (2a and $2 b$ ) respectively, take their reference from the NPs that precede them and can be analyzed as anaphor. It is interesting to note that in (2a), the 3rd person plural possessive pronoun ame 'their' refers to the NP Ataa Kwei ke eya "Ata Kwei and his wife" both the pronoun and the conjoined NP are in the same clause/sentence. The 3rd person plural subject pronoun am $\varepsilon$ "they" takes its reference from the NP Ataa Kwei ke ena ke ame shaayoo "Ataa Kwei and his wife and their in-law". The antecedent NP and the anaphor however, are in different sentences. The pronouns agree in number and person with their antecedents. 


\section{THE CONCEPT RECIPROCAL CO-REFERENCE}

Reciprocity expresses the notion that ' $\mathrm{X}$ acts on $\mathrm{Y}$ and $\mathrm{Y}$ acts on $\mathrm{X}$. This refers to a situation where there are two or more people who are doing the same thing to one another. Mazegia (2012:7) opines that " reciprocals are conceptually similar to reflexives; in both cases, the agent is at same time a patient which in effect results in argument reduction from both semantic and syntactic viewpoint". In Ga this is achieved by means of a possessive pronoun + he construction (this we shall call the reciprocal marker) the verb can be single or reduplicated. We shall see in our next section that the possessive pronoun + he structure is the same as what is employed in reflexive constructions. . Reciprocal marker involves a plural pronoun when its antecedent is plural.

Consider the examples in (3). In (3a, 3b and 3c) are extracts from texts in the bible. We have used brackets to enclose the clauses that contain the reciprocals and their antecedents for easy reference. This text is taken from both the Ga and the English bible.

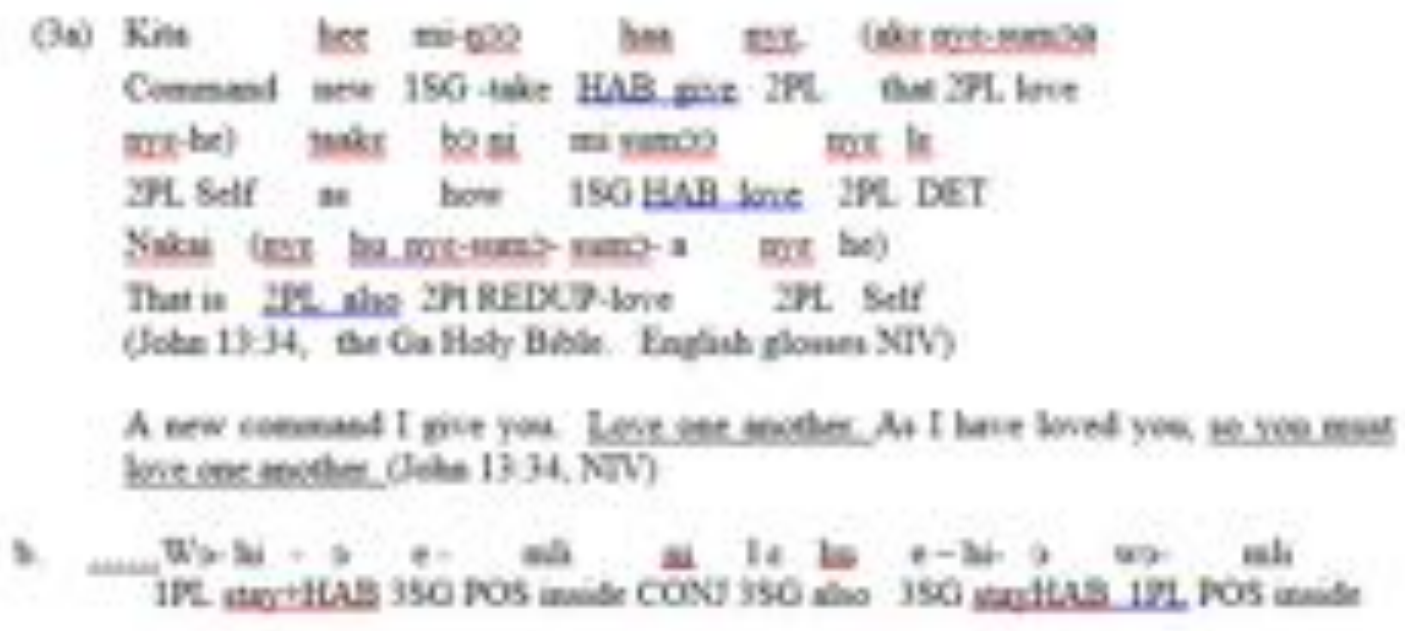



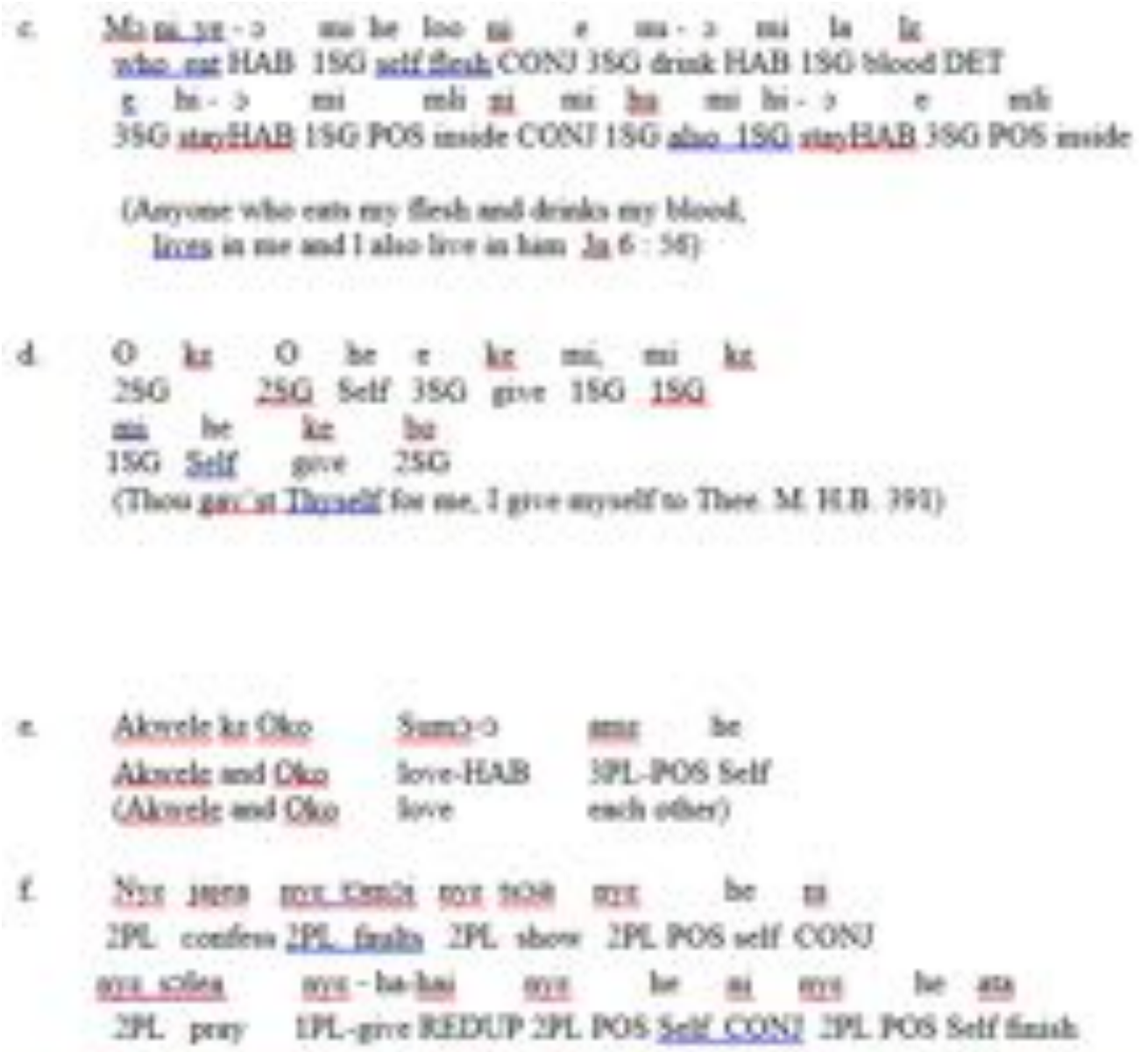

(So then, confess your sins to one another and pray for one another, so that you will be healed) (James 5:16, NIV)

The examples in (3a), (3b), (3c) and (3d) involve imperative constructions while those in (3e) and (3f) involve ordinary declarative. In each case, however, an NP that serves as the antecedent of the reciprocal element is syntactically expressed. In all the examples, the plural personal pronoun plus he 'self' structure is used, for example, nyche "yourselves" amehe "themselves". womli our heart' If we should consider the example in (3d) one could find that the sentence is ambiguous. Thus Akwele ke Oko sumэว amshe could be interpreted as: "Akwele and Oko are in love" or Akwele loves Oko and Oko loves Akwele" what probably could change that perception a little may be the names used because Akwele and Oko are twin names in Ga.

Mazegia (2012: 7) opines that "reciprocal are conceptually similar to reflexives; in both cases, the agent is at the same time a patient which in effect results in argument reduction from both semantic and syntactic viewpoint" Instead of two distinct Agent-Patient relations which would result in four participants, the argument would be limited to only two, i.e. Agent- patient as well as the relation as illustrated in (3e) above.

\section{The Concept Reflexive Co-reference}

Reflexive refers to a process where, in a construction, the subject and the object relate or refer to the same entity Crystal (2008: 408). Haspelmath, \& Sims (2012: 239) argues that the reflexive is a valence changing operation where the agent and the patient are co-referential, and can be seen as occupying a single syntactic function. This process involves the action of the verb affecting the same person who performs the action. Reflexives are used by languages to 
express the notion of ' $\mathrm{X}$ ' acts on $\mathrm{X}$ '. The languages of the world use several ways to express reflexive co-reference. Naden (n.d) as quoted by Saah (2006), states that the languages of the world exhibit several possibilities in the way they mark reflexives.

The reflexive item mostly used is he self or body. It is an abstract nominal. It has no function apart from the reflexive. The use of the reflexivity may be expressed by the use of special verbs. (i.e VP marking) and reflexive markers. In Akan for example, the reflexive is formed by a combination of the personal pronoun and the word for body (e.g. me ho 'myself', wo ho ' yourself' etc.) see Saah (2006). This is not different from the Ga expression of reflexive. The Ga reflexive is also formed by a combination of the personal pronoun and the word for body (e.g. mi he 'myself', wo he 'yourself', e he 'her/himself'). Haspelmath \& Sims (2012) express the rule underlying this construction as put in Fig 1

Fig 1
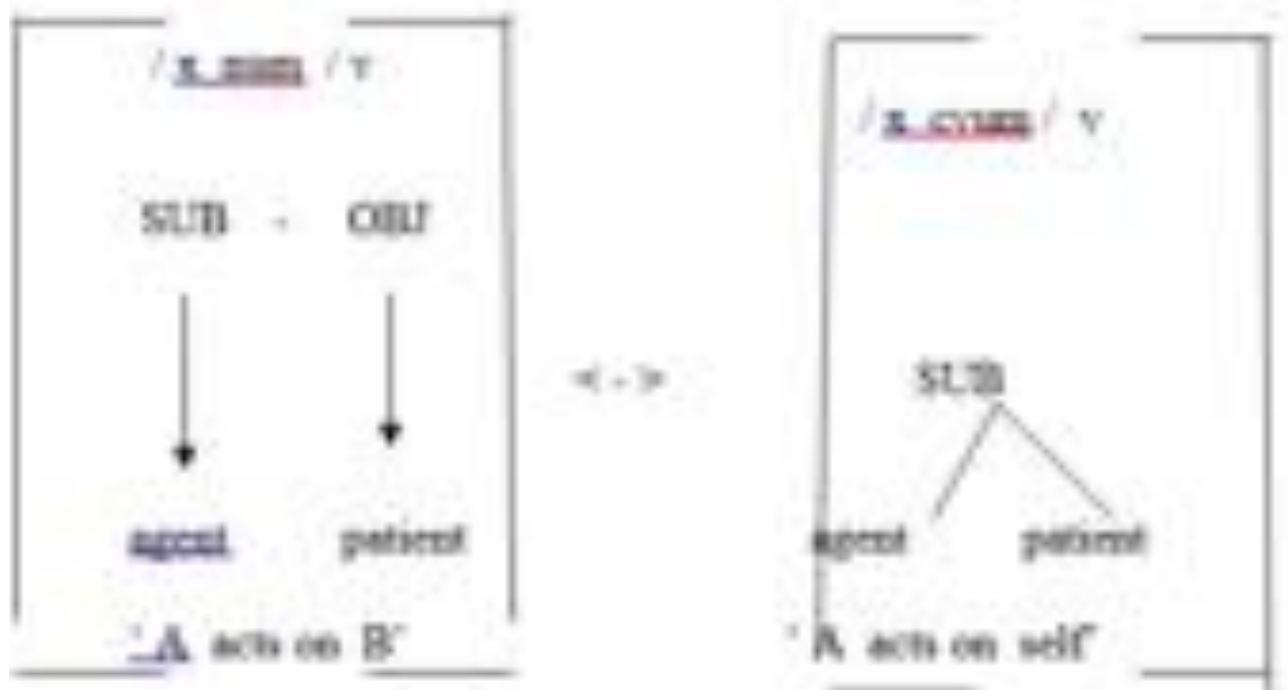

They assert that in the reflexives, the meaning of the verb remains the same, but both the agent and the patient are co-referential with the same index as shown in the word - schema in Fig 1.

\section{Verbs that can be used transitively / intransitively}

From the verbs used in our examples, it appears that Ga language allows some form of VP marking of reflexives and this involves the choice of a particular type of verb. Saah (2006) classified those verbs as special kinds of verbs.

Only few verbs are used in this section. The verbs we use to refer to body activities include the following verbs; "jwen to think", tua to insert a medicine in the anus, sa "to douche' These are two place predicate that require a subject (which performs the role of an Agent) and an object (which performs the role of a Theme). However, most of these verbs can be used without an overt object. In Ga the verbs that indicate grooming of the body have to add he self and most often the object is covert. Let us consider the following examples with the verbs 'sa' to douche and tua which can be transitive or intransitive verbs. 


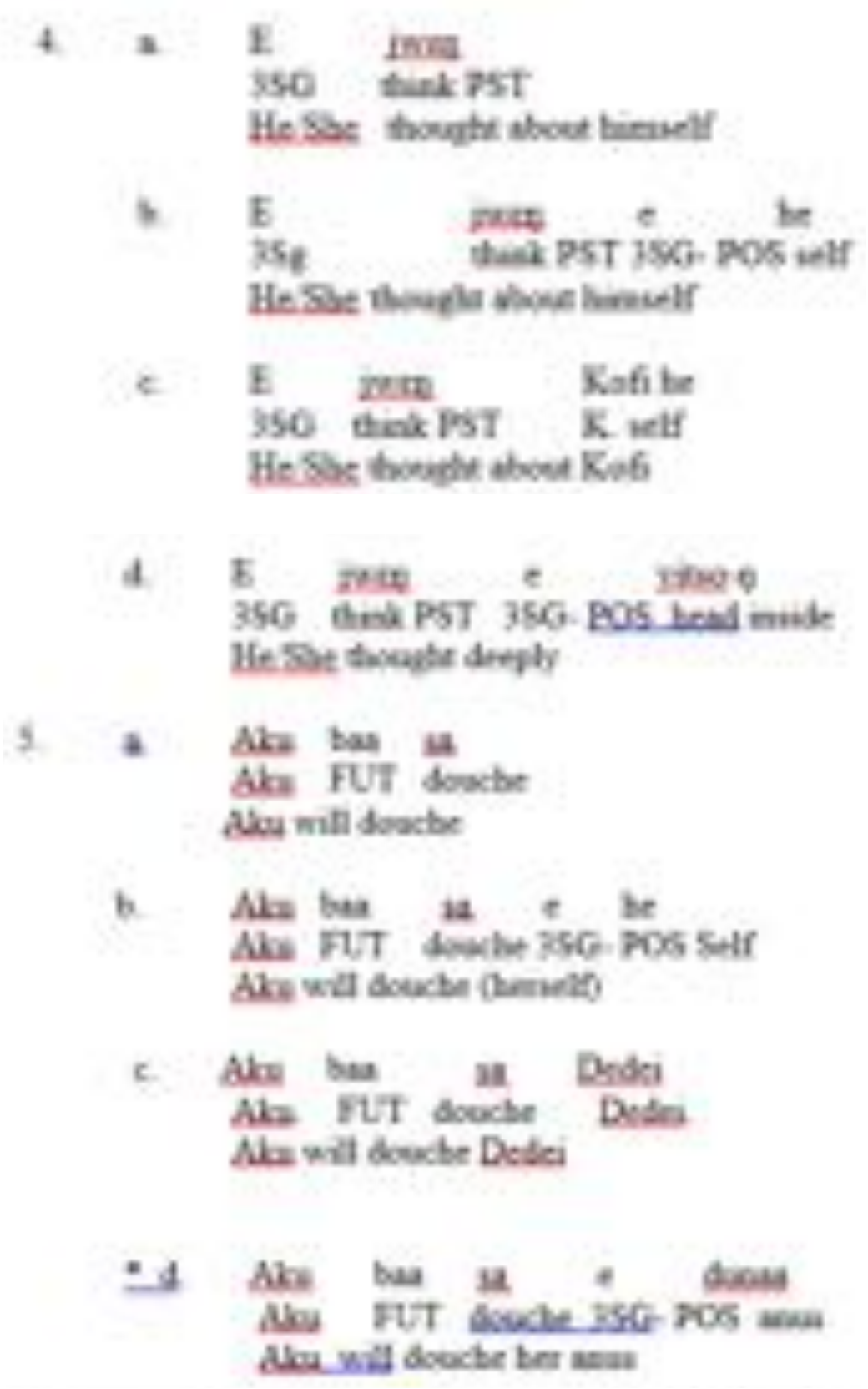

The examples in $4 b \& c$, and $5 b \& c$, show that the verbs used are transitive. However, the illustrations in $3 \mathrm{a}$ and $4 \mathrm{a}$ make the verbs intransitive and when used, the interpretation is always given that the subject (Agent) is understood to be acting upon himself or herself. (ie the subject NP is construed as both the Agent and the Theme). This makes the object of the verb covert.

It is always possible to use the possessive pronoun + he body/self-construction in reflexive body verb as in sentences (4b) and (5b). In such constructions, there is not much to choose between a reflexive reading and one in which the subject/agent is doing something to a part of his/her body. The part of the body that is affected by the action may be mentioned as described by the verb in sentences $4 \mathrm{~d}$, however, in $5 \mathrm{~d}$ the part of the body affected by the verb may not be mentioned. In the Ga language, when the verbs tua or sa is mentioned, the part of the body where the medicine is to be applied is known. 


\section{Reflexive Markers}

Reflexives are morphologically marked with a possessive pronoun + the morpheme he which translates literally as 'body' This is very relevant in the Ga language because the reflexive is marked with a possessive pronoun + the morpheme he (ie self/body). This may be explained as a type of NP marking of reflexives. We may claim that, Ga is one of the languages that employ the use of possessed nominal for reflexives. Looking at the examples given the same form that means "body" is used to mark reflexives. Sung (2006:7) quoted in Saah (2006) confirms this by stating that abundant cross-linguistic evidence suggests that the derivation of reflexive markers from expressions of body parts is a common development of semantic change, either diachronically or synchronically: For instance, Haitian uses the noun 'tet' 'head'... old French uses 'cors' 'body' with a possessive pronoun ...some of the African languages use the noun self or body as reflexive anaphors...."

This clearly shows that Ga is no exception in the use of constructions involving body parts which mark reflexives.

Let's consider the examples below.

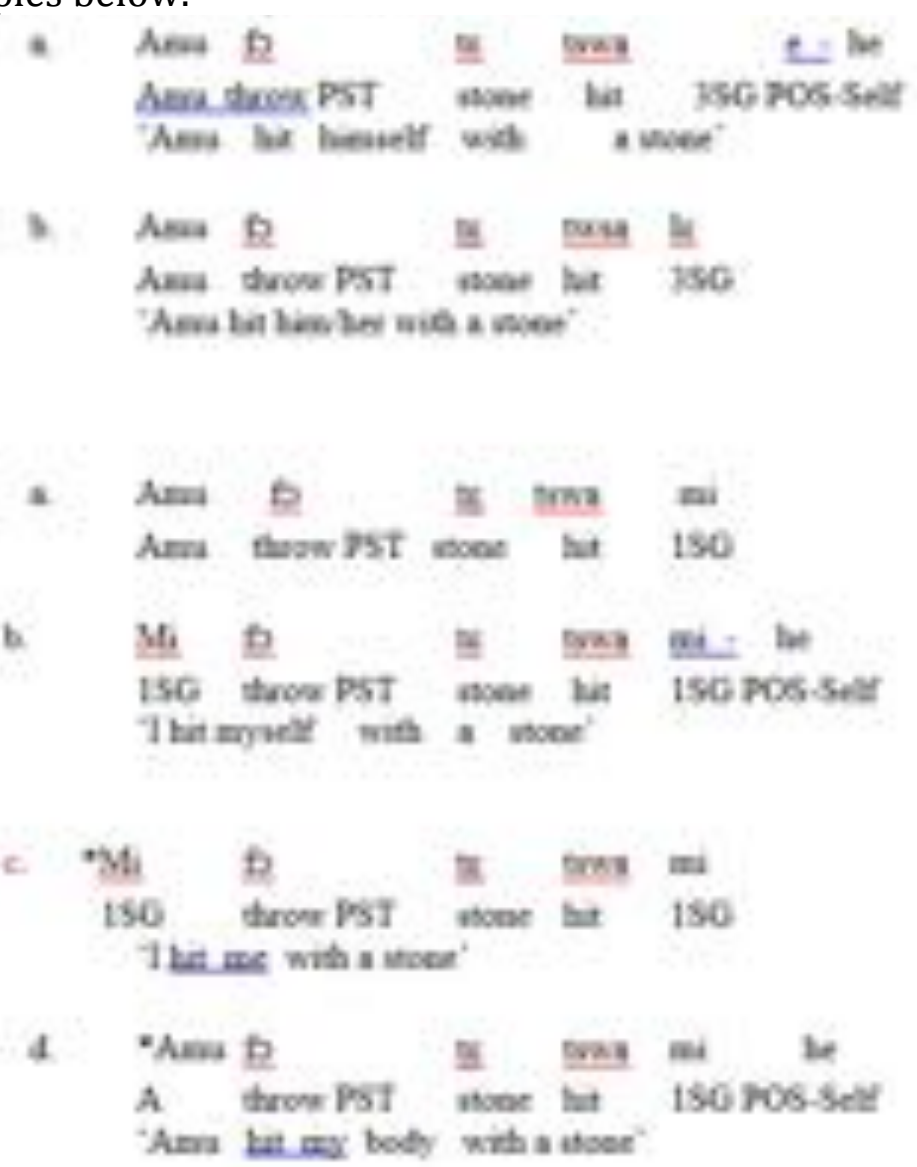

The examples in (6) and (7) reveal the facts about Reflexivization in Ga. To start, the possessive pronoun + he gives a reflexive reading only when there is an antecedent NP within the sentence to which it may be co-indexed. Thus (6a) e -he 'himself' may be co-indexed with the antecedent NP, Amu (which happens to be the subject of the sentence), giving a reflexive reading. It cannot be interpreted as referring to some other person outside the sentence.

In (7b) mi-he 'myself' may be co-indexed with the antecedent pronoun, mi 'I' and no other entity outside the sentence. Both examples give the idea that the entities are interacting with themselves. The reflexive and its antecedent agree in person and number. The reflexives in 
(6a) and (7b) are 3rd person and 1st person singular respectively and so are their antecedents. It just happens that wherever we have a reflexive, the possessive pronoun + he structure occurs in the same domain, (i.e in the same sentence) as the antecedent.

Secondly, pronoun forms without he (self) cannot occur where the conditions for Reflexivization are met. From the examples, where a reflexive pronoun is used, a simple personal pronoun or a full NP with the same purported reference is excluded.

Thus le "him/her in (6b) cannot refer back to the subject NP. Amu neither does the pronoun in (7c). Both of them refer to entities outside the sentence. Though, the pronoun mi ' $\mathrm{I}$ ' in the sentence is syntactically ill-formed. This shows that when the conditions for Reflexivization are met, the rule must be applied if it is not applied, the result would be unacceptable because the sentence will be ungrammatical.

\section{EXPLANATION OF ANAPHORS}

The generative syntax in Chomskyian tradition (Chomsky 1981) has a component of the grammar, the binding theory, which deals with the explanation of NPs. Anaphors, as we have seen are one of the three types of NP identified in generative grammar. We shall see whether the binding theory makes the right predictions about the explanations of anaphor in Ga.

\section{Binding}

To describe the relationship between an anaphor and its antecedent, we consider the notion of binding, which states that an anaphor must be bound. Culcover and Jackendoff (2005:217) assets that "binding is a semantic relation, fixing one phrase's reference in terms of another'. The binding theory has received various formulation studies. We will adopt Carnie (2013), formulation of the binding theory:

\section{Binding}

$A$ binds $B$ if and only if

A c-commands B and A and B are co-indexed
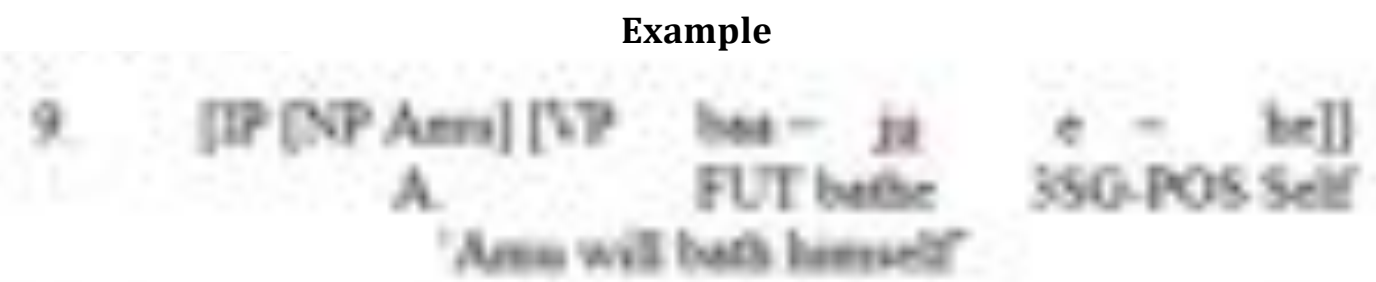

The NP Amu C-commands the Pos+ he constructed, e -he 'himself' in (8) is co-indexed with it. e - he is therefore bound by the NP Amu. This means that e-he takes its interpretation from $\mathrm{Amu}$, its antecedent.

There are situations where an anaphor-like element and a possible antecedent may occur in separate sentence. In such situations, the Binding Theory, as posited in (8) is not enough in solving the problem of interpretation. The anaphor and its antecedent must occur in a particular syntactic context for the proper explanation of the anaphor. To account for such situations, the locality condition of anaphor was postulated. 


\section{Locality condition on the Binding of Anaphor}

There is a constraint on the occurrence of an anaphor and its antecedent can be from other. This is referred to as the Locality condition on the Binding of Anaphor and it is stated in Binding Principle A:

Binding Principle A

Anaphor must be bound in its binding domain (Carnie 2013: 155, ex 22)

Binding Domain

The clause containing the NP (anaphor, pronoun

R-expression) (Carnie 2013: 154, ex 21)

Binding Principle A: as formulated above show that if an NP is to be interpreted as an anaphor, the NP and its antecedent must occur in the same clause (ie, its binding domain) for example in (9), the antecedent NP Amu and the reflexive e -he (herself) both occur in the same sentence (IP) where Amu c-commands and is co-indexed with e-he.

Given this explanation, we can now tackle the issue of how anaphors, especially, reciprocals and reflexives are interpreted in Ga. We shall look at situation where pronouns function as anaphors. It must be noted, however, that pronouns may, but need not, be bound. Carnie (2002:19) gives the following characterization of pronouns:

\section{PRONOUN}

An NP that may (but need not) get its meaning from another word in the sentence (Carnie 2002:91). To explain this, it means that pronouns can optionally get their meaning from another NP in the sentence, but they may also get their meaning from somewhere also.

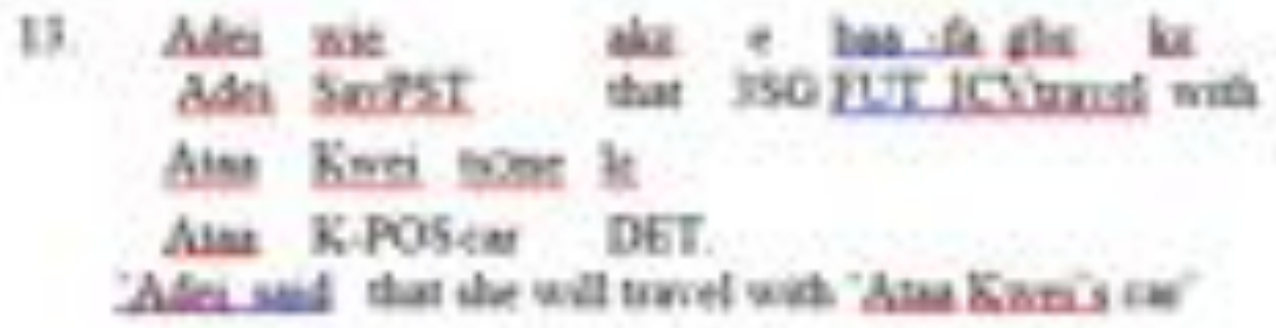

The subject pronoun e 'she' is co-referential with the subject of the sentence, Adei. It cannot be construed with any other entity and can therefore be said to be an anaphor. Here, the notion of locality does not apply as the pronoun and its antecedent occur in separate clauses. This agrees to the definition of a pronoun in (I3). Let us consider the case of reciprocal. There are examples of anaphors that must obey Binding Principle A.
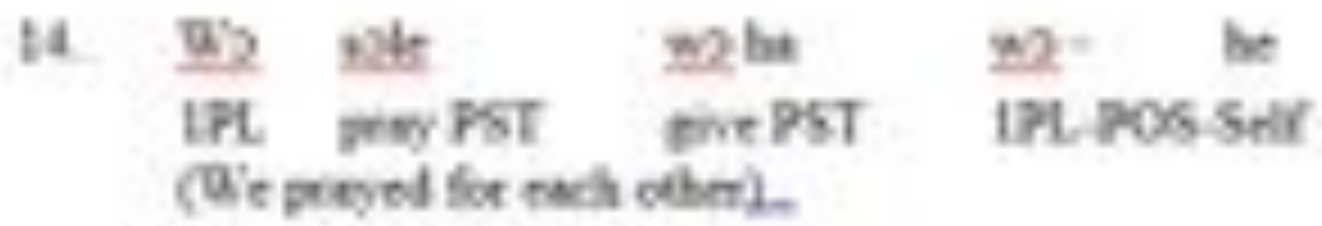

The reciprocal marker here wo+ he 'each other' or 'one another' is bound by the subject pronoun wo 'we'. The two are in the same binding domain. Wo+ he is not referring to any other entity outside the sentence. Looking at the examples given, we can conclude that the binding theory specifically Principle A makes the right prediction about the interpretation of reciprocals in Ga. 
When we consider reflexives, Saah (1989) assets that there are certain complex structures in which the possessive pronoun + he structure can be construed as co-referential to the subject of both the matrix and the embedded clauses. This posits ambiguity in such situations especially between a reflexive reading as in himself/herself/itself (when one entity is acting upon himself/ herself) and another interpretation involving entity acting upon another person. In the second reading the possessive pronoun the structure invariably refers to the body or part of the body as the referent that is, his/hers/it or 'near him/her/it.

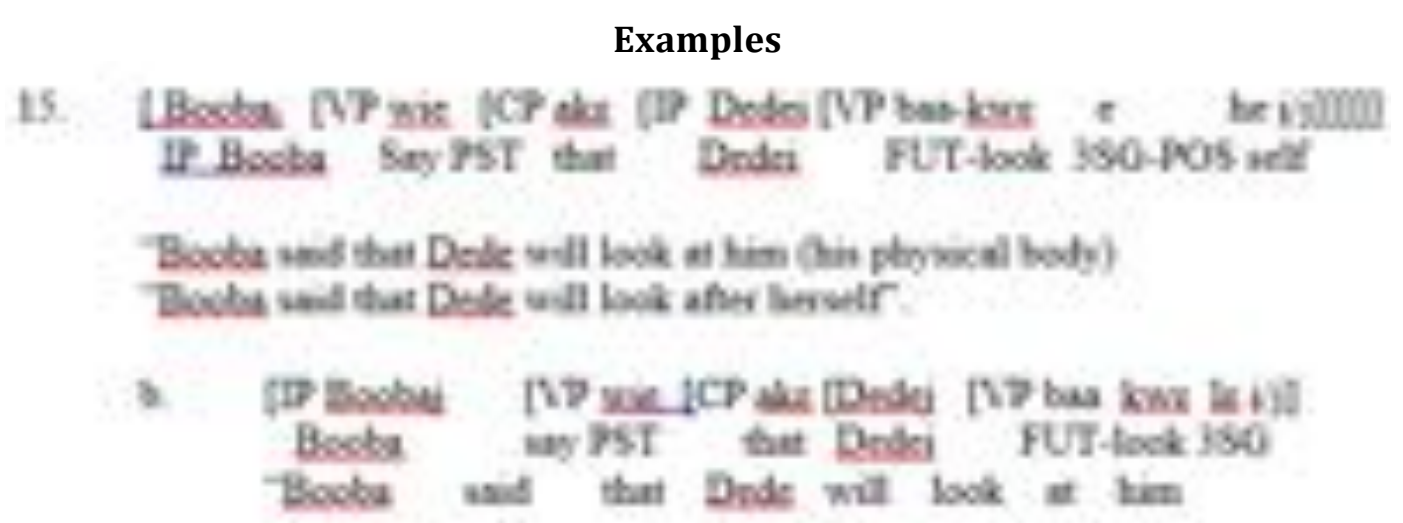

In example (15a) e-he can be coindexed with either Booba the subject of the matrix clause or Dede the subject of the embedded clause. A reflexive interpretation is ruled out in the first place, because it violates the locality condition on the interpretation of anaphors; e-he and Booba appear in different or separate clauses. We can paraphrase this as: "Booba said that Dede will look at him" can mean "his body" and any connection with the reflexive are coincidental. In the second clause within the same sentence, Dede is co indexed with e-he. We have a reflexive reading here because both Dede and e-he occur in the same binding domain. (ie the same clause containing the subject NP Dede and e-he, thereby satisfying Binding Principle A, which regulates the interpretation of anaphors.

In the case of (15b), the pronoun le 'him' is coindexed with Booba, reflexivization is not possible because the two NPs do not occur in the same local domain and the pronoun le is not constructed with Booba.

Looking at the verb like wie 'to say' which select an NP/Pos+he complement, we can resort to Binding Principle A to separate a reflexive reading from a non-reflexive one let us consider the examples in (16) below:

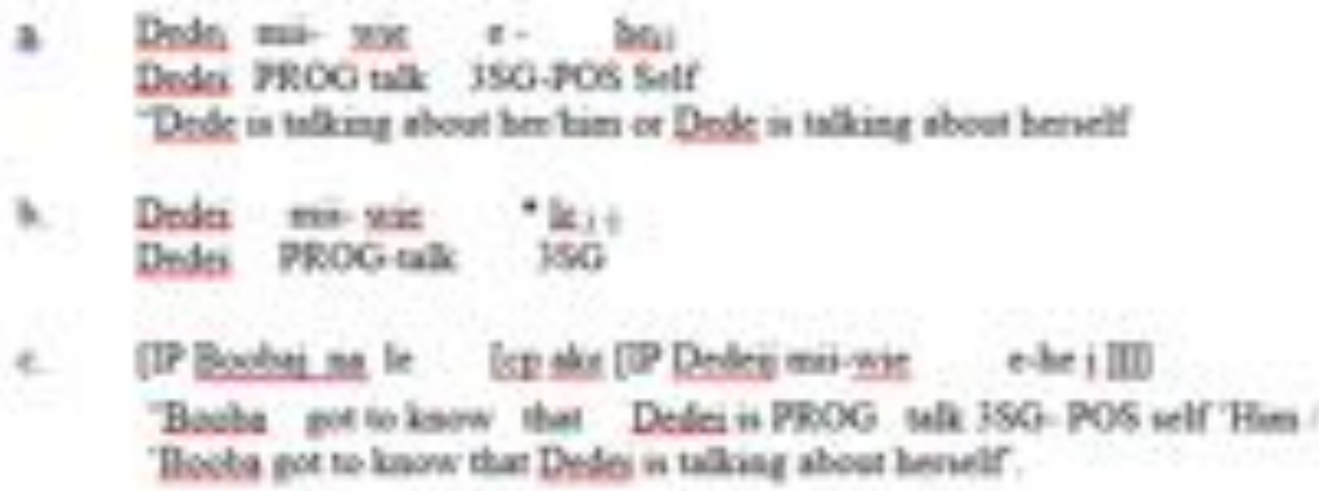

The sentence (16a) is ambiguous e-he can be interpreted as referring to Dedei, in which case, have a reciprocal reading 'Dedei is talking about herself'. It can also be interpreted as referring to somebody outside the sentence. In such reading the notion of reciprocity is absent; e-he is there because it is a necessary feature of the complement option of the verb. (16b) shows that 
a plain pronoun cannot occur as the complement of the verb "wie" to talk" (16c) shows that both Booba and Dedei can be coindexed with e-he. When Booba is coindexed with e-he, we do not get a reflexive reading because the two NPs do not occur in the same binding domain. The English translation reads: "Boobaj got to know that Dedeij is talking about himj. "But when Dedei is coindexed with e-he, we had a reflexive reading: "boobaj got to know that Dedeij is talking about herself. This is an instance where the complement option of the verb coincides with the conditions for Reflexivization. Thus in this instance e-he may be interpreted as reflexive, because, since the subject of Dedei, talking is herself, it satisfies the notion of 'an entity interacting with him/herself' it is interesting to note that on this reading both e-he and Dedei are in the same local domain thereby satisfying the requirements of Binding Principle A.

The examples given in (15) and (16) show that Binding Principle A makes the right predictions about the interpretation of reflexives in Ga.

\section{CONCLUSION}

This paper has revealed how anaphoric relations are expressed in Ga. It has shown that pronouns can be anaphoric when they have an antecedent in the same sentence or in a particular context. Reciprocal relations, has also been demonstrated, they are expressed with verbs and plural possessive pronouns plus he 'self' construction as the reciprocal marker. It is realized that both single and reduplication of verbs is evident in reciprocal reading in the Ga language. This study is quite similar in a way when compared to the study in Akan.

Reflexives show covert and overt objects in their constructions and a possessive pronoun plus he "self" marker. The possessive pronoun agrees in number and person with the antecedent. It has been demonstrated also that binding principle A, which deals with the interpretation of anaphors, makes the right predictions about the interpretation of anaphoric elements in Ga.

The findings in this study can be replicated in some related languages or compared to other languages to examine the similarities or differences of these intricate processes. It can also stimulate further studies in syntax, morphology, and morphosyntax.

\section{References}

Agbedor, P. (2014), The Syntax of Ewe Reflexive and Logophoric Pronoun: In A Legon Reader in Ghanaian Linguistics. (Eds ), (pp. 51-65). Ayebi Clarke Publication.

Carnie A. (2002), Syntax: A generative introduction. 2nd edition,Oxford. Blackwell Publishers.

Carnie A.(2013), Syntax: A generative introduction. 3rd edition. Malden, MA and Oxford: Wiley Blackwell.

Culicover, P. W. and R. Jackendoff (2005), Simpler Syntax. Oxford: Oxford University Press.

Chomsky (1995), The Minimalist Program MA: MIT Press.

Chomsky (1981), Lectures on government and binding. Dordrecht: Foris.

Crystal, D.( 2008), A dictionary of linguistics and phonetics. Oxford: Blackwell.

Haegeman, L.(2006), Thinking Syntactically: A guide to argumentation and analysis. Malden, MA, Oxford, U.K \& Victoria, Blackwell Publishing.

Haegeman, L. (1991), Introduction to government and binding. Oxford. U.K. Blackwell Publishing.

Haspelmath, M. \& D. A. Sims (2012). Understanding Morphology. (2nd Edition). London: Hodder Education.

Menzengia, S. (2012), Valency in Ambaric and Oromo reflexives and reciprocals. htt: etd.aus.et.

Osam, K. (2002), Reflexive Marking and. Related Functions, in Journal of Asian and African Studies, 64: $141-151$. 
Osam, K. (2014), Reflexive Marking and Interpretation in Akan. In A Legon Reader in Ghanaian Linguistics, (Ed) 37 - 50. Ayebi Clarke Publication.

Reuland, E. (2001), Pronouns, Primitives of Binding. In Binding Theory: Terms and Concepts. The Blackwell Companion to Syntax Vol 1 (Ed) by Martin Everaert, Henk Va Van Riemsdijk 2006. Blackwell Publishers Ltd.

Saah, Kofi K. K. (2006), Proceedings of The Annual Colloquium of the Legon-Trondheim. Linguistic Project.

Saah, Kofi K. K. (2007), Anaphora in Akan. In M. E. Kropp Dakubu, G. Akanlig-Pare, E. Kweku Osam and Kofi K. Saah(Eds), Studies in the Languages of the Volta Basin 4.2: 23- 35.

Williason. K.(1989). Niger- Congo Overview. In J. Bendor- Samuel (ed), The Niger- Congo Languages:

AClassification and Description of Africa's Largest Family, pp 3-45. Lanham: University Press of America. 